\section{Obstructive sleep apnoea with Arnold-Chiari malformation}

\author{
M J Doherty, D P S Spence, C Young, \\ P M A Calverley
}

\begin{abstract}
A case of obstructive sleep apnoea associated with the Arnold-Chiari malformation is described, in which the loss of pharyngeal sensation seems to have played an important part in the aetiology of the obstruction of the upper airway.

(Thorax 1995;50:690-691)
\end{abstract}

Keywords: obstructive sleep apnoea, Arnold-Chiari malformation, airways obstruction.

Obstructive sleep apnoea usually arises when anatomical factors narrow the upper airway or lead to an increase in negative intraluminal pressure. However, most reports of sleep disorders in patients with neuromuscular disease have found central sleep apnoea ${ }^{12}$; obstructive episodes have been reported in some $\mathrm{e}^{34}$ but not all $^{5}$ cases where sleep apnoea coexists with an Arnold-Chiari malformation.

Arnold-Chiari malformation is a disorder in which the cerebellar tonsils herniate through the foramen magnum producing variable signs and symptoms of cerebellar, cervical, and/or brainstem dysfunction. Surgical correction of this problem has been reported to produce a dramatic improvement in the symptoms of the associated sleep apnoea, but follow up has been relatively brief. ${ }^{3}$ We report a case of obstructive sleep apnoea associated with Arnold-Chiari malformation where mechanisms other than upper airway narrowing appeared to operate, and where a longer follow up has led us to revise our initially optimistic view of surgical treatment.

\section{Case report}

A 62 year old man presented with two "black outs", one following a coughing bout. He admitted to hypersomnolence and was a loud snorer. His wife had witnessed apnoeas during sleep, together with attacks of coughing and choking. He was mildly overweight with a collar size of 16 inches $(40 \mathrm{~cm})$ and body mass index of $27 \cdot 4$, but no neurological abnormality was detected at presentation. A provisional diagnosis of cough syncope together with obstructive sleep apnoea was made and polysomnography was performed. This showed repeated obstructive apnoeic episodes (table) irrespective of body position associated with considerable difficulty in swallowing saliva during his sleep. Nasal continuous positive airway pressure was tried but was not tolerated.

At follow up three months after presentation he reported progressive difficulty in walking. On examination he had a positive Romberg's sign and dysarthria. Over the next few weeks he developed diplopia and, subsequently, difficulty in swallowing. At this point his gag reflex was noted to be absent, whilst horizontal and vertical nystagmus together with features of cerebellar ataxia were present.

Myelography and magnetic resonance imaging (MRI) of his head and cervical spine revealed an Arnold-Chiari malformation with the cerebellar tonsils prolapsed to $\mathrm{C} 2$. There was kinking of the medulla by the inferior tip of the clivus, but no hydrocephalus or syrinx were demonstrated.

He underwent a preliminary tracheostomy followed by a decompressive laminectomy to $\mathrm{C} 2$ and debulking of both cerebellar tonsils. Postoperatively his swallowing was good and pulse oximetery with an open tracheostomy revealed no oxygen desaturations during sleep. Three months after closure of this tracheostomy he was no longer sleepy and had no problems with choking or nocturnal swallowing of saliva. His gag reflex had improved, as had his perception of pharyngeal sensation, although this was still not normal.

Repeat polysomnography showed a considerable improvement in his sleep apnoea when lying on his side but worse when supine. However, the events that persisted were still obstructive in character (table). Repeat MRI showed the development of a syrinx in the upper cervical spine but this was not thought to be clinically significant.

He remained well until 10 months after his operation when he developed severe bilateral aspiration pneumonias for which he required admission to the intensive care unit. He had three further episodes of pulmonary aspiration despite the use of a "safe" swallowing technique. His hypersomnolence became clinically troublesome again two years after his surgery and repeat polysomnography (table) showed significant obstructive apnoeas in all sleeping positions and more sleep disruption. At this time his gag reflex was completely absent and he lacked all pharyngeal sensation to touch. Three years after surgery he suddenly died in his sleep. Post mortem examination showed that death was due to a further large aspiration. 


\begin{tabular}{|c|c|c|c|}
\hline & Preoperative & $\begin{array}{l}\text { Three months } \\
\text { postoperative }\end{array}$ & Two years postoperative \\
\hline Total sleep time (min) & 293 & 320 & 394 \\
\hline Time to sleep onset $(\mathrm{min})$ & 12 & $8 \cdot 5$ & 12 \\
\hline Time in sleep stages 1 and $2(\%)$ & $80 \cdot 2$ & $47 \cdot 6$ & $47 \cdot 5$ \\
\hline Time in sleep stages 3 and $4(\%)$ & $13 \cdot 6$ & $20 \cdot 3$ & $34 \cdot 2$ \\
\hline Time in REM sleep (\%) & $6 \cdot 2$ & $32 \cdot 2$ & $18 \cdot 4$ \\
\hline No. apnoeas and hypopnoeas/hour & 54.9 & $11 \cdot 5$ & $31 \cdot 7$ \\
\hline Total no. apnoeas/hour & $49 \cdot 8$ & $5 \cdot 1$ & $22 \cdot 2$ \\
\hline No. central apnoeas/hour & 1 & $0 \cdot 4$ & 0.5 \\
\hline No. EEG arousals/hour & $25 \cdot 6$ & $4 \cdot 9$ & $10 \cdot 8$ \\
\hline Mean duration of obstructive apnoeas (s) & 40.5 & $29 \cdot 7$ & 24 \\
\hline Minimum $\mathrm{SaO}_{2}$ during sleep (\%) & $47 \cdot 1$ & $57 \cdot 3$ & $63 \cdot 9$ \\
\hline
\end{tabular}

\section{Discussion}

Respiratory disturbances are now well recognised in patients with Arnold-Chiari malformation. Initial reports in children pointed out the risk of aspiration and the potential for vocal cord paralysis, ${ }^{6}$ a problem not seen in our patient. In 1985 Balk et al described an adult with the Arnold-Chiari malformation and central sleep apnoea, ${ }^{5}$ but three subsequent reports have described patients where obstructive sleep apnoea predominates as in our case. ${ }^{346}$ An important difference was that the gag reflex was absent with the obstructive apnoeas, but was present in the patient described by Balk et al. ${ }^{5}$ Topical anaesthesia of the upper airway has been shown to increase the time to arousal during obstruction of the airway $^{7}$ in normal subjects and to increase the number of obstructive events in snorers. ${ }^{8}$ The mechanisms involved in this are not completely understood but are thought to involve the protective upper airway reflex. Increased negative intraluminal pressure during obstruction of the upper airway stimulates oropharyngeal mucosal mechanoreceptors which form part of the vagally mediated afferent limb of the reflex, the efferent limb of which results in an increase in the action of dilating muscles in the upper airway to maintain airway patency. By blocking the afferent limb, anaesthesia of the upper airway will therefore result in a loss of this reflex.

Our patient provides a naturally occurring example of this effect with a large reduction in the number and duration of apnoeas parallelling the improvement in cerebellar function and partial return of his gag reflex, with a subsequent deterioration in his breathing at night as the reflex protection declined. Clearly other mechanisms reflecting brainstem ischaemia may have been important initially in the development of his obstructive sleep apnoea. However, the relatively static MRI appearances and clinical tests of cerebellar function after surgery suggest that his relapsing sleep apnoea was due to the loss of his gag reflex, emphasising the potential for reflex mechanisms to contribute to this condition. Posture is also important as significantly more obstructive events occurred when the patient slept on his back, even after surgery. These data suggest that the reflex response may be particularly imporant in maintaining airway patency when supine.
Surgical treatment of the Arnold-Chiari malformation can produce dramatic improvement in cerebellar function ${ }^{9}$ and a similar improvement in sleep apnoea has been reported by Levitt and Cohn. ${ }^{3}$ However, the clinical problem was less severe in their case (apnoea + hypopnoea index approximately 14 per hour) compared with 54.9 per hour in our case, and no further follow up was reported. Our patient's progress suggests that the severity of the obstructive sleep apnoea and the degree of recovery of glossopharyngeal nerve function will determine the outcome. Although the symptoms of sleep apnoea recurred in our patient two years after surgery, the major hazard to the patient was the continued risk of aspiration pneumonia, as demonstrated by his untimely death. Early recognition of sleep apnoea in a patient with the Arnold-Chiari malformation may avoid the otherwise unpredictable risk of respiratory arrest, ${ }^{10}$ but our experience suggests that continued surveillance is needed even after apparently successful surgery.

We are grateful to Professor David Chadwick and Mr Gordon Findlay for the important part they played in the care of this patient and for allowing us to report some of their findings.

1 Smith P, Edwards R, Calverley PMA. Mechanisms of sleep disordered breathing in chronic neuromuscular disease; implications for management. $Q \mathcal{F}$ Med 1991;81:96-102.

2 Teelucksingh S, Steer CR, Thompson CJ, Seckl JR, Douglas NJ, Edwards CR. Hypothalamic syndrome and central sleep apnoea associated with toluene exposure. $Q f \mathrm{Med}$ 1991;78:185-90.

3 Levitt P, Cohn MA. Sleep apnoea and the Chiari I malformation: case report. Neurosurgery 1988;23:508-10.

4 Cirignotta F, Coccagna G, Zucconi M, Gerardi R, Lugaresi A, Cortelli $\mathrm{P}$, et al. Sleep apnoeas, convulsive syncopes and autonomic impairment in type I Arnold-Chiari malformation. Eur Neurol 1991;31:36-40.

5 Balk R, Hiller C, Lucas E, Scrima L, Wilson FJ, Wooten V. Sleep apnoea and the Arnold-Chiari malformation. $A m$ Rev Respir Dis 1985;132:929-30.

6 Ruff M, Oakes J, Fisher S, Spock A. Sleep apnoea and voca cord paralysis secondary to type I Chiari malformation. Pediatrics 1987;80:231-4.

7 Basner RC, Ringler J, Garpestad E, Schwartzstein RM, Sparrow D, Weinberger SE, et al. Upper airway anaesthesia delays arousal from airway occlusion induced during human NREM sleep. $\mathcal{f}$ Appl Physiol 1992;73:642-8.

8 Chadwick GA, Crowley P, Fitzgerald MX, O'Regan R, McNicholas WT. Obstructive sleep apnoea following topical oropharyngeal anaesthesia in loud snorers. Am Rev Respir Dis 1991;143:810-3.

9 Mohr P, Strang FA, Sambrook MA, Boddie H. The clinica and surgical features in $\mathbf{4 0}$ patients with primary cerebellar ectopia (Arnold-Chiari malformation). $Q 7 \mathrm{Med} 1977$; 181:85-96.

10 Fish DR, Howard RS, Wiles CM, Simon L. Respiratory arrest: a complication of cerebellar ectopia in adults. Neurol Neurosurg Psychiatry 1988;51:714-6. 